\title{
Promoción y Municipalización en el Occidente Bético'
}

\author{
Juan Manuel CAMPOS CARRASCO \\ Javier BERMEJO MELÉNDEZ \\ Nuria DE LA O. VIDAL TERUEL \\ Universidad de Huelva. Área de Arqueología
}

\begin{abstract}
Resumen
El proceso de romanización del extremo occidente bético, lo que ocupa hoy día el territorio onubense, ha vivido en los últimos años una revisión, y en la mayor parte de los aspectos, el inicio en la investigación del periodo romano. En esta línea, a continuación se presenta un estudio sobre la promoción jurídica de las ciudades del mismo sobre las que se precisaba realizar una síntesis diacrónica y comparativa en lo que a la obtención de su municipalización se refiere, desde el territorio de la sierra y el puerto de Onoba, donde se dejan sentir las medidas de Augusto, hasta las ciudades de la campiña deudoras de la extensión del ius latii vespasianeo.
\end{abstract}

Palabras Clave: Municipalización, colonias, arqueología romana, territorio onubense.

\section{Summary}

The process of romanization of the Western extreme of the Provincia Baetica, the current Huelva's territory, has lived in recent years a review, and in most respects, the beginning of the Roman period research. In this line, then, an analysis on the juridical promotion of the cities of this territory is presented, from the point of view of a diachronic and comparative synthesis in connection with their municipalization, from the territory of the mountains and the Onoba's port, where the measures of Augustus are felt, to the cities of the countryside, in debt to the extent of the Vespasian's ius latii.

Keywords: Municipalization; coloniae; Roman Archaeology; Huelva's territory (SW Spain)

\section{INTRODUCCIÓN}

Las contribuciones del Profesor Bendala a los estudios sobre los procesos urbanos en Hispania y especialmente en la Bética, han sido decisivas, abriendo nuevas perspectivas de la investigación en este campo. Desde los primeros trabajos que de esta línea de investigación publicó hace más de dos décadas (Bendala et alii, 1987; Bendala,

1 El presente trabajo se enmarca dentro de las actividades de los proyectos de investigación "Análisis de la implantación y evolución del fenómeno urbano en el Suroeste peninsular: Arqueología Urbana en la Ciudad de Huelva. (II ${ }^{a}$ Fase)". Ministerio de Ciencia e Innovación (Ref. HAR2008-04666-
1989) hasta el más reciente (2009) que sirvió de introducción a la tercera edición de la clásica obra de García y Bellido Urbanística de las grandes ciudades del mundo antiguo (1969) han sido muchos los trabajos relevantes (entre otros: Bendala, 1990; 1994; 1998; 1999; 2000-2001; 2003 a y b; 2005 y 2009; Abad y Bendala, 1996), que han ido conformando un valiosísimo cuerpo de información sobre el tema.

HIST), perteneciente al Plan Nacional de $\mathrm{I}+\mathrm{D}+\mathrm{i}$ y "Ciudades romanas del territorio onubense" (Ref. P07HUM-02691), correspondiente a la convocatoria de Proyectos de Excelencia de la Consejería de Innovación, Ciencia y Empresa de la Junta de Andalucía. 
Es en esta línea en la que desde el Área de Arqueología de la Universidad de Huelva hemos venido trabajando desde hace años, animados por el apoyo que el Prof. Bendala, con su presencia en esta universidad, siempre nos ha brindado.

Los estudios sobre las ciudades en el área onubense eran prácticamente inexistentes hasta hace apenas dos décadas cuando comenzamos el estudio del Fenómeno Urbano en nuestro territorio desde sus orígenes en el Bronce Final Tartésico (Campos y Gómez, 1995), siguiendo así una corriente de opinión iniciada por M. Bendala (1989), hasta la Antigüedad Tardía. En los últimos años nuestros esfuerzos se han centrado fundamentalmente en el periodo romano, abordando de este modo el estudio de todas las ciudades implantadas en el territorio onubense desde época prerromana (entre otros: Campos, 2005, 2009 a y b, 2011; Campos y Vidal, 2003; Campos, Gómez y Pérez, 2006; Vidal, 2007; Campos y Bermejo, 2007, 2010; Bermejo y Campos, 2010; Bermejo, 2011). Esta línea de investigación, que no sólo se ha limitado a estudiar los aspectos propiamente urbanísticos, sino que trasciende hacia los urbanos, ha incorporado recientemente estudios sobre la promoción jurídica referidos al territorio serrano, la Baeturia Celtica, a través del análisis de la ciudad de Arucci (Bermejo, 2011; Campos y Bermejo e.p.) y del puerto atlántico de Onoba (Campos, Vidal y Ruiz, 2010 y Campos, 2011).

En este homenaje al Prof. Bendala, al que nos sumamos con gran placer, hemos encontrado la ocasión para hacer extensible el estudio de la promoción y municipalización a todo el extremo occidental de la Bética.

\section{El OcCidente Bético una tierra de CONTRASTES}

La situación que Roma encuentra a su llegada al territorio occidental de la futura Provincia Baetica, lo que actualmente conforma el territorio onubense, era diversa dándose diferentes patrones de asentamiento y grupos poblaciones a lo largo del mismo. Esta diferenciación, producto en buena medida de una división corológica tripartita - campiña, andévalo y sierra-, obligó a la administración romana a poner en marcha distintos programas de implantación en lo que a su modelo administrativo, económico, territorial y jurídico se refiere, dando origen con ello a un patrón de asentamiento caracterizado en algunas zonas por la presencia de unas fuertes estructuras indígenas enmarcadas en un secular mundo urbano, y en otras por la práctica inexistencia del mismo (Campos y Vidal, 2003).

A este respecto, la zona de la Sierra supondría un modelo de ocupación e implantación en el que convergen unas particularidades concretas y diferenciadas del resto del entorno minero y de la campiña-costa, con grupos poblaciones de celtici, protagonistas de las insumisiones contra el poder de Roma en la guerras de conquista del s. II a.C., y posteriormente en las confrontaciones civiles, sertoriana, en la primera mitad del s. I a.C., y en las luchas entre Pompeyo y Cesar, a mediados de la misma centuria. Este sustrato poblacional y cultural, con el particular devenir histórico de los acontecimientos, así como la inexistencia del modelo urbano, aconsejaban a Roma un planteamiento, primero de conquista y posteriormente de implantación específicos, en un territorio tradicionalmente conflictivo, inseguro, donde urgían medidas que pasaban por la colonización con población ciudadana que sirviera de punta de lanza de la romanidad en el territorio, y en última instancia de la fundación de una ciudad, que introduciría a este territorio en el sistema urbano, la civitas, piedra angular de la administración romana, en la que se unen lo fiscal, judicial, religioso y político. Ello no pudo llevarse a cabo hasta que las condiciones políticas en Roma lo permitieron, esto es, tras César y especialmente con su sucesor Augusto, en el contexto de las medidas de repoblación y promoción jurídica llevadas a cabo en su plan para la integración de las comunidades provinciales, al menos en los primeros momentos de su principado. Éste es el proceso que se desarrolla en el área serrana, presentando una temprana promoción para la ciudad de Arucci, en el contexto de estas medidas.

Por su parte, el distrito minero supuso un modelo de implantación diferente. Las riquezas del distrito minero no pasarán desapercibidas a la administración romana, la cual encontraba aquí un pilar económico fundamental. Es por ello que, ya desde época republicana, se constata la explotación de las minas de Riotinto y Sotiel Coronada, quedando como testigos de esta actividad, para estos momentos, numerosos escoriales. A medida que avance el s. I a.C. y en los momentos del prin- 
cipado de Augusto, la producción aumentará alcanzando su máximo apogeo, manteniéndose hasta momentos del s. II d.C. El sistema de control pasaba por un dominio ejercido directamente por funcionarios imperiales, procuratores. Por tanto todo el territorio minero se constituiría como un gran fundus exceptus donde no se dará el florecimiento de la vida municipal (Pérez, 2006: 75), eje axial de la política de asimilación de Roma. El descubrimiento de las tablas de Vipasca, distrito minero de Aljustrel, ha proporcionado una fuente excepcional para conocer el modelo administrativo desarrollado en estos cotos mineros. El modelo de implantación pasaba por la existencia de pequeños poblados mineros ubicados a pie de mina o en sus proximidades, con lo que se daría una alta concentración de pequeños $v i c i$, ya que las grandes masas de mineralizaciones y pequeños afloramientos no sobrepasan el kilómetro y medio. Pero dependiendo de la envergadura del yacimiento minero podían alcanzar la superficie de muchos municipios, de modo que "el desarrollo urbano no está reñido con el estatuto jurídico", simplemente, dado que la autonomía municipal no garantizaba una mayor producción se prefirió el sistema de administración directa por parte de funcionarios imperiales (Pérez et alii: 2009: 40). De entre todos estos poblados destacarían Urium (Riotinto) y Rubrae (Tharsis), desde donde se dirigiría la administración de estos distritos, y en los que se encontrarían las funciones administrativas y de gestión con espacios de representación y muestras de culto a la casa imperial, como atestiguan las esculturas de Riotinto (Schattner, 2007).

Finalmente el territorio que comprende la Tierra Llana se configura como uno de los espacios en los que Roma no verá la necesidad de llevar a la práctica la concesión de privilegios como uno de los pilares en los que se basará su modelo de implantación, dado que aquí la administración romana encuentra un desarrollado mundo urbano, con unas estructuras de articulación del territorio herederas en última instancia del periodo cartaginés, fuertemente jerarquizado $\mathrm{y}$ administrado, con un sustrato cultural y poblacional turdetano mucho más permisivo al cambio de potencia dominadora, llevándole a adoptar un modelo de implantación totalmente diferente al que desarrollará en la sierra, Ahora bien, dentro de este último territorio se encontraría la excepción del puerto de Onoba, el cual, a buen seguro, pudo obtener una concesión de privile- gios importante con motivo de su ascenso colonial según las nuevas interpretaciones de los indicios y textimonios existentes.

\section{LAS PROMOCIONES AUGUSTEAS: LA FUNDA- CIÓN DE ARUCCI Y EL ASCENSO COLONIAL DE ONOBA AESTUARIA.}

Como enunciábamos en la introducción, en el área de la sierra la administración romana encontrará un poblamiento muy diferente al existente en la zona de la Tierra Llana. Allí se reproduce un patrón de asentamiento disperso, con poblaciones de celtici emparentadas con los celtas de la meseta y que tradicionalmente habían mostrado una actitud de insumisión y rebeldía a la administración romana. Así, una vez liquidado el periodo de guerras civiles, Roma entenderá que el proceso de implantación pasaba por una ocupación efectiva del territorio, donde las medidas de colonización con poblaciones ciudadanas, hispanas e itálicas, junto con la fundación de una ciudad, eran las premisas esenciales que asegurarían el éxito de la empresa. A este respecto dichas medidas no pudieron llevarse a cabo hasta momentos del principado de Augusto quien, para el caso concreto hispano, dedicó importantes esfuerzos en la organización de las nuevas provincias con reajustes territoriales, administrativos y por supuesto judiciales, donde la concesión de derechos se convertiría, al menos en los primeros momentos de su gobierno, en uno de los pilares fundamentales en la intención de crear un mapa jurídico privilegiado acorde a los planes de cambios que se estaban desarrollando en Hispania en el marco de su segundo viaje tras el fin de las guerras cántabras. En este contexto histórico de importantes cambios administrativos y judiciales de fines del s. I a.C., es donde podemos establecer la fundación y promoción municipal de la ciudad de Arucci Turobriga, en la zona meridional de la Baeturia Celtica, cuyos últimos estudios e investigaciones llevan, con todas las manifestaciones que la envuelven -territoriales, urbanísticas, religiosas, etc.- a proponer una promoción jurídica para momentos augusteos, muy en relación con el momento de su fundación (Campos, 2009 a y b; Campos y Bermejo, 2010; e.p; Bermejo, 2010; 2011; Bermejo y Campos 2010; e.p).

Esta hipótesis se ha visto refrendada por diversas pruebas e indicios. A este respecto, a nivel arqueológico no existen dudas para la fundación de la ciudad, la cual ha sido establecida en 
momentos augusteos del cambio de era, en relación con las medidas de cambios territoriales y administrativos anteriormente comentados, y que encuentra otros ejemplos fundacionales en el suroeste como el caso de Emerita y Pax Iulia. Para el caso concreto del enclave de Arucci Turobriga, éste surgirá como producto de una contributio de ambos núcleos célticos en una fundación ex novo en el llano. De ello se extrae la idea de que Roma acometerá sobre la base indígena preexistente su programa de establecimiento del mundo urbano, y en éste será Arucci la portadora de la comunidad política o populus -de ahí su pervivencia en las fuentes-, mientras Turobriga lo hará de manera contribuida.

De ello se deriva el hecho de que no se entendería todo este programa de asentamientos de poblaciones ciudadanas, colonos venidos de otras zonas hispanas, en un territorio endémicamente conflictivo, con un importante programa de fundación, reajustes territoriales, administrativos y en última instancias jurídicos (contributio), si no es otorgando a esta ciudad los privilegios jurídicos necesarios para dotarse de los mecanismos municipales ineludibles para llevar a buen término el establecimiento de la estructura urbana y todos los aspectos que encierra. Además, y en línea con nuestra argumentación, contamos con más evidencias que permiten apoyar una promoción augustea para este enclave.

En este sentido, por un lado, hay evidencias de la existencia de ciudadanos adscritos a la Galeria tribus, que si bien serían incolae al proceder de otras zonas de Hispania tal y como evidencia el ambiente epigráfico funerario, a buen seguro actuarían como agentes de primer orden en la municipalización del núcleo. Además contamos, previa a la llegada de estos ciudadanos adscritos a la Galeria tribus, con individuos en el territorio poseedores de la ciudadanía, la cual queda reflejada en los cognomina de la zona, como los Sertorii y Iulii, así como en la composición de sus tria nomina, producto de la creación de redes clientelares en los episodios de las guerras civiles, de las cuales, especialmente del primero de ellos, se tienen bien constatados ejemplos en este territorio de la sierra onubense. Todo ello nos está

2 Creemos que esta sala correspondería al lugar de reunión del Ordo de la ciudad, constituida como municipio, siendo poco probable que se tratara del lugar de reunión de un sena- revelando la existencia de población ciudadana, poseedora del ius latii concentrada en el territorio aruccitano para fines del s. I a.C., momento en el que la administración romana está llevando a cabo la fundación de la ciudad en el llano.

Por otro lado, se constatan muestras de adhesión o manifestaciones de culto dinástico a la domus augusta documentadas para momentos del segundo cuarto del s. I d.C. A este hecho estarían haciendo alusión las inscripciones de Germánico, procedente del foro, y de Agripina, esposa de aquél, la cual conformaría junto con la de su marido sendas dedicaciones, ubicadas en el mismo lugar, a los descendientes del Divo Augusto (Campos y Bermejo, 2007; 2010).

Muy en relación con estas dedicaciones públicas honoríficas se encuentra un intenso programa de monumentalización de la ciudad. Ahora, para momentos del segundo cuarto del s. I d.C. se está construyendo el foro de la ciudad, dotándose de los espacios de representación propios de los municipios, y sentando en la curia un ordo decurionum ${ }^{2}$.

Con ello entendemos que el tradicional argumento empleado para establecer, en momentos en los que las investigaciones en el yacimiento y el entorno aún eran parcas, una municipalización flavia para esta ciudad de la sierra pierde fuerza. Esta interpretación basaba su exposición en la existencia de la inscripción de la Civitas Aruccitana, entendiendo que dicho concepto de civitas estaría haciendo alusión a un enclave peregrino. Sin embargo, esta hipótesis no debe ser tenida en cuenta de manera tan categórica ya que tal concepto sirve para designar tanto a ciudades peregrinas como privilegiadas y cuenta con un alto viso de ambigüedad (Le Roux y Trannoy, 1973: 222; Stylow, 1995: 107, cit, 13). Además resulta tremendamente llamativa la inexistencia, de ser un municipio flavio o que se generase un proceso de promoción flavia en la sierra, de un ambiente epigráfico propio de momentos de la segunda mitad o último tercio del s. I d.C. A este respecto es de subrayar como en la colección epigráfica del territorio occidental de la sierra, una de las mejores y más numerosa de la actual pro-

do local o consejo de notables indígena, dado que el ambiente epigráfico, así como las evidencias arqueológicas y arquitectónicas así lo avalan. 
vincia onubense, no existen manifestaciones de adhesión o muestras de culto dinástico o imperial para los emperadores flavios y ninguno de sus familiares, en favor de los personajes/príncipes Julio-Claudios o posteriores Antoninos. En la misma línea se podría argumentar como, mientras se constatan los individuos portadores del cognomen Sertorii o Iulii, y adscritos a la Galeria tribus, no se ha registrado ni un solo testimonio de la Quirina, indicio inequívoco de una promoción para momentos flavios (Bermejo, e.p). Por todo lo cual, y aún a la espera de futuras aportaciones epigráficas, se cuenta con más indicios para proponer una promoción del enclave próxima a los momentos de su fundación, siendo ésta producto de las medidas de Augusto.

Por lo que respecta al núcleo de Onoba, éste seguiría a Gades en su posición ante la nueva potencia dominadora, salvaguardando sus intereses económicos, comerciales, etc., tal y como sucedió con el resto de oppida de la campiña onubense, durante el proceso de conquista e inaugurando la segunda centuria hasta mediados del I a.C., en la misma línea con respecto a etapas precedentes, deduciéndose una continuidad (Pérez, 2006: 53). Durante este periodo Roma mantendría probablemente a las élites locales enriquecidas al amparo del comercio marítimo, los recursos mineros y pesqueros, sin introducir cambios sustanciales en una ciudad que mantendría su papel hegemónico. Sería sólo en los momentos de mediados del siglo I a.C., y en el contexto de las medidas de César y posteriormente de Augusto, en la ya nueva Provincia Baetica, cuando pudo alcanzarse la promoción de este enclave a municipio o colonia. En este sentido han sido numerosos los autores que han tratado el tema sobre la condición jurídica de Onoba, intentando perfilar el estatuto jurídico que pudo disfrutar este enclave, el cual poco a poco empieza a mostrar un periodo romano con cada vez más presencia. Henderson, en su ya clásico trabajo sobre Julio César y el ius latii, siguiendo las descripciones de Plinio y Marcial, donde la ciudad aparece cognominada como Onoba Aestuaria, en una clara descripción sobre su ubicación en un ambiente de estuarios, considera que el sobrenombre no hace

3 En una muy afinada apreciación el autor llama la atención sobre como en época contemporánea ha sucedido una dinámica similar, en el desarrollo de la cual en la ciudad se asen- referencia a ningún tipo de promoción jurídica, sino simplemente a una consideración geográfica al estar situada en la desembocadura de los ríos Tinto y Odiel, con lo que, para él, la adscripción de Onoba con algún estatuto colonial es dudosa (Henderson, 1942: 7). Para Knapp, por su parte, en la ciudad sería fácilmente conjeturable la existencia de un Conventus Civium Romanorum, surgido al amparo de los emigrados itálicos, hombres de negocios atraídos por el comercio y las perspectivas empresariales que ofrecían las minas (Knapp, 1977: 151). Allí donde en las ciudades provinciales los itálicos estaban presentes en cierto número, tendían a conformarse en comunidades, las cuales podían decidir acciones en conjunto, siendo denominadas como Conventus en los cuales el poder e influencia de sus miembros con los gobernadores romanos y otros grupos de ciudadanos los hacía políticamente importantes. Éstos no constituían órganos de gobierno local, pero sí comunidades de itálicos que se autogobernaban (Brunt, 1977: 220).

Ello denotaría como el enclave onubense no pasó desapercibido desde los primero momentos de la implantación de Roma, siendo un punto estratégico en la red comercial del SO peninsular, y en el que se podría intuir, siguiendo a Knapp, que se hubieran establecido ciudadanos itálicos o romanos, que posteriormente hubieran desarrollado un papel decisivo en la posible promoción de la ciudad. En los mismos términos se expresa Thouvenot (1940/1973: 193, 184), para quien resulta extraño que Roma se desinteresara de este enclave con una ubicación tan importante, al ser el único establecimiento portuario entre la desembocadura del Anas y Gades, e igualmente reconoce que el comercio de las riquezas mineras que debió controlar no pasarían inadvertidas a la emigración itálica ${ }^{3}$. Igual posicionamiento siguen algunos autores, al opinar que las perspectivas comerciales que supondría Onoba debieron ser apetecidas por la emigración latina, acogiendo un importante grupo de hombres de negocios, y pudiéndose intuir la existencia de ciudadanos en el puerto onubense (Vidal, 2007: 183). Ello estaría en relación con la dinámica migratoria que se produce durante los momentos republicanos pre-

taron colonias inglesas, francesas y belgas al amparo de la comercialización del mineral proveniente de la zona andevaleña (Thouvenot, 1940/1973: 194 cit. 1). 
cesarianos, cuando el progresivo desarrollo de las relaciones comerciales entre la Península Ibérica y la Itálica dará lugar a que numerosos comerciantes romanos e itálicos se asienten en aquellos centros urbanos que poseían una situación adecuada para el desarrollo de las transacciones (Marín, 988: 57; Knapp, 1977: 151, 152).

Por otro lado, el descubrimiento de los lingotes del pecio Planier 4 (Benoît, 1962: 154,156, fig. 19) uno de los cuales, al menos, porta inscripción - y en cuyas diferentes interpretaciones no vamos a ahondar (Domergue, 1990: 285; Laubenheimer, 1973: 37) quedándonos con la restitución más aceptada de una mención colonial (González y Pérez, 1987; González, 1989: 129; Gómez y Campos, 2000: 124; Vidal, 2007: 184) - supuso el primer aporte epigráfico en el que posiblemente se esté haciendo indicación del estatuto colonial de Onoba. En esta línea se están decantando las últimas investigaciones sobre el puerto atlántico, indicando una posible promoción para la ciudad al rango de colonia, probablemente para momentos augusteos, tal y como parece desprenderse de los nuevos testimonios arqueológicos e interpretaciones de todos los datos que actualmente se conocen (Campos, Vidal y Ruiz, 2010)4.

Pese a todo, lejos de esclarecerse el debate, recientemente se ha vuelto a proponer un estatuto municipal - y en este caso flavio - para el puerto atlántico, el cual pasaba por adscribir al núcleo de Onoba una inscripción procedente de una explotación agraria contemporánea a caballo entre los términos municipales de Gibraleón y Huelva (Gimeno, Martín y Pérez, 2010). Dicha inscripción, un ara cilíndrica fechada para momentos del 75 o inmediatamente posteriores, en la que un ciudadano - de la Quirina tribus tras el desempeño de sus cargos (aedil, duovir) en un acto de agradecimiento costeó y consagró

4 A este respecto habría que hacer mención al Proyecto donde se enmarcan estas últimas investigaciones, "Análisis de la Implantación y Evolución del fenómeno urbano en el Suroeste Peninsular: Arqueología urbana en la ciudad de Huelva (II fase)" (Ref.-HAR2008-04666).

5 El que la pieza no conserve la parte en la que se especificaba a quien estaba consagrada impide conocer más detalles sobre este supuesto, sin embargo no sería descabellado el relacionar esta dedicación como un acto de agradecimiento, en ámbito urbano, por la consecución de la ciudadanía el ara a alguna divinidad o emperador divinizado (¿Vespasiano?) $)^{5}$ (Bermejo y Vidal, 2009), procede ciertamente de un contexto urbano pero indeterminado, es decir, no se tiene constancia de la procedencia o lugar del hallazgo exacto de la pieza, con lo que afirmar tan categóricamente una promoción flavia para Onoba por la aparición de un epígrafe descontextualizado resulta un tanto imprudente, más aún cuando el lugar de aparición, una finca contemporánea próxima a una villa bajoimperial ubicada en una encrucijada de caminos, lleva a plantear que su lugar de procedencia pueda ser igualmente, o con mayores visos de probabilidad dada la municipalización flavia de la campiña, alguno de los oppida de la Tierra Llana igualmente próximos al lugar del hallazgo. Además, de aceptar la propuesta de estos autores, donde en ningún momento se aprecia una relación directa entre dicha inscripción y la ciudad de Onoba, ¿no sería igualmente válido aceptar la procedencia onubense del famoso, e igualmente próximo, puteal de trigueros en el que sus dedicantes aparecen adscritos a la Galeria tribus y por tanto serían indicadores de una promoción augustea?. Como vemos el argumento para proponer una municipalizción flavia para el enclave de Onoba tan sólo por la existencia de una inscripción descontextualizada pierde fuerza, más aún cuando las nuevas interpretaciones apoyadas en los datos arqueológicos, históricos y literarios apuntan en la dirección de una promoción al rango de colonia para el puerto onubense (Campos, Vidal y Ruiz, 2010). Parece pues, que las hipótesis de una promoción jurídica al estatuto de colonia para la ciudad de Onoba dentro del proceso de reformas que Augusto puso en marcha en Hispania cada vez más, con el peso que las nuevas investigaciones e interpretaciones están aportando, se intuyen de una manera más nítida.

romana. La pieza mantiene un formulario que la asemeja a los ejemplos constatados para momentos flavios entre el 75 y el 84 d.C., quizás más cercano a la segunda fecha, dado que el dedicante presenta un cursus normalizado, habiendo necesitado tiempo para desempeñar el edilato y el duvirato, incluso autores como Stylow creen que esta disposición de un cursus directo normalizado solo podría ser instituido por las leyes municipales (Stylow, 1986: 299 cit 30), datadas en época domicianea. 


\section{LA MUNICIPALIZACIÓN FLAVIA DE LOS OPPI- DA DE LA TierRa Llana}

A diferencia del territorio anteriormente analizado, la zona de la campiña onubense mostrará sustanciales diferencias con respecto al proceso de promoción jurídica. Sin entrar en profundidad en la dinámica y el comportamiento que tuvo este territorio ante la conquista y la imposición de stipendia establecidos por Roma en los que se aprecia una evolución a lo largo del s. II a.C. sin mayores traumas, a excepción del levantamiento del 197 a.C. que fue secundado por importantes núcleos el Valle del Guadalquivir intuyéndose, incluso, la que todavía debía ser una muy importante influencia cartaginesa (Bendala, 1995: 63) y que no sería ajena a las ciudades de la campiña y costa onubense, Onoba (Huelva), Ilipla (Niebla), Ostur (Mesas del Castillo, Manzanilla), e Ituci (Tejada La Nueva, Escacena), podría decirse que ésta viene representada a grandes rasgos por una continuidad en relación con el periodo anterior. En líneas generales, el comportamiento de estos núcleos durante el proceso de conquistas, salvo para el caso de Ilipla, tal y como se documenta en sus niveles de incendio y destrucción (Campos, Gómez y Pérez, 2006: 343, 344), parece mostrar una rendición, sin episodios traumáticos (deditio in fidem), más que una conquista propiamente dicha (deditio in dicionem), lo que posibilitó que estas ciudades conservaran sus senados locales, legislación, y cierta autonomía, a excepción de sus territorios, que ahora pasaban a engrosar el ager publicus de Roma (Pérez, 2006: 33). De ello se deduce que las ciudades del territorio onubense de la Tierra Llana entraron en la órbita romana siendo civitates stipendiaria, desarrollando a lo largo del s. II y prácticamente el s. I a.C. sus modos de vida propios, manteniendo su sistema cultural frente a una administración romana más interesada en el cobro y recaudación de impuestos que en modificar los patrones culturales de las comunidades turdetanas.

La Tierra Llana, a diferencia de la Sierra y el Andévalo, es un mundo de ciudades, de oppida, en la tónica del territorio del Valle del Guadalquivir, con una articulación del territorio jerarquizada donde destacan núcleos urbanos y centros menores de producción dependientes de aquéllos, lo que configuró un proceso diferenciado del modelo de implantación que Roma pondrá en marcha en el norte, con el desarrollo de unas medidas de colonización, implantación del terri- torio, etc. que tendrán como máximo exponente la cristalización de una promoción jurídica, paradójicamente, mucho más tardía que para el caso del núcleo de Arucci, tal y como se evidencia en los testimonios de Quirina tribus rastreables en el ambiente epigráfico de los oppida turdetanos del territorio, como más adelante se analizará, y que dejan entrever la mano de la extensión del ius latii vespasianeo. En esta línea nos vemos obligados a intentar dilucidar cuál fue el desarrollo histórico que enmarca este proceso, en el cual los interrogantes, más que las respuestas, son los protagonistas.

A simple vista resulta llamativo como siendo un territorio que no muestra especial oposición al proceso de conquista, con una tradición urbana secular, que rápidamente pasa, sin especiales roces, a incorporarse en el nuevo sistema de control romano, el proceso de municipalización se produzca en momentos flavios, no encontrándose indicios de una promoción jurídica cesariana o augustea. Como ha quedado expuesto, el comportamiento de estas ciudades en el proceso de conquista, el sustrato cultural, y el tradicional sistema urbano que Roma encuentra a su llegada a la Tierra Llana, constituían un caldo de cultivo propicio para, una vez que se hubieran producido las reformas de Cesar y Augusto, haber podido promocionar adoptando, en un claro síntoma de romanidad, los mecanismos administrativos municipales que permitirían su entrada en el mapa de derecho jurídico romano, pasado a engrosar la nómina de ciudades privilegiadas, modificando sus espacios urbanos con el desarrollo de una incipiente urbanística a la romana - como se constata para otras ciudades turdetanas - donde las élites locales se irían convirtiendo en las detentoras de los resortes del gobierno municipal a la romana, ingresando paulatinamente y tras el desempeño de una magistratura en los ordines.

Sin embargo, las evidencias indican que los viejos núcleos turdetanos tuvieron que esperar a la extensión del derecho de ciudadanía flavio para alcanzar la categoría jurídica de municipia, con lo que parece que estos oppida pasaron desapercibidos y fueron elementos ajenos al proceso de promoción jurídica de momentos de fines de la república y el principado de Augusto. En este sentido podríamos traer a colación el ambiente epigráfico de la Tierra Llana en el que se constatan dedicaciones de ciudadanos adscritos a la Quirina tribus, junto con testimonio de ordines, formulacio- 
nes ob honorem, etc. las cuales resultan tremendamente claras y no dejan lugar a dudas sobre su promoción gracias a la extensión del ius latii Vespasianeo. De ello, que podamos deducir que a lo largo del último tercio del s. I d.C. los viejos oppida pasarían a un ordenamiento municipal de tipo romano, donde los individuos, partiendo de la condición de latinii, adquirirían la ciudadanía romana tras el desempeño de alguna magistratura. Roma no tendría que esperar a que se crearan los cargos típicamente romanos para otorgar el grado de municipalidad a una ciudad sino que a partir de la concesión del latium, los "instituta" indígenas se irían transformando en magistraturas romanas (Andreu, 2004: 10). El proceso municipalizador Flavio en el marco de la Tierra Llana ha sido tratado en diversas obras. Así en algunas de carácter general, de temática epigráfica o jurídica, se recogen los cambios producidos por el ius latii Flavio en estas ciudades (González, 1989; Andreu, 2004; Morales, 2003). Incluso han visto la luz algunos estudios con un carácter más específico, aunque también es verdad, sobredimensionando la actuación de dichas medidas, y ubicando municipios flavios allí donde existiese algún testimonio de Quirina tribus, siendo la nómina de municipia ignota extrañamente elevada (Morales, 2001).

Con ello, de entrada se dibujan dos modelos diferentes de promoción jurídica en el territorio onubense - Arucci junto con Onoba y las ciudades de la Campiña- que denotan la puesta en práctica de políticas distintas como consecuencia de realidades preexistentes diversas, pero ¿por qué se propició tan tarde la integración jurídica de las comunidades turdetanas de la campiña? ¿no hubiera sido más lógico pensar en una temprana promoción para los oppida de la Tierra Llana antes que para el entorno de la sierra, territorio tradicionalmente conflictivo, donde el mundo urbano es ajeno hasta la llegada de Roma?.

Las respuestas a estas preguntas residirían en las características que rodean la implantación de Roma, así como la evolución de los oppida a municipia en la Tierra Llana onubense y que son las propias del área turdetana. Como ya apuntara S. Keay, (1992: 295) parece que Roma hasta aproximadamente mediados del s. I a.C., tuvo un pequeño impacto sobre el desarrollo social, político y la vida cultural de las comunidades turdetanas. Las pocas medidas administrativas implementadas por Roma durante el s. II a.C. fueron esencialmente pasivas y supusieron el reforza- miento y mantenimiento de la estructura previa, reflejando la superficialidad que constituyó la cultura romana en este periodo, a lo que habría que sumar una cierta resistencia por parte del mundo indígena al cambio cultural. Ello nos lleva de antemano a la idea ampliamente tratada, sobre que la administración romana amortizó las estructuras precedentes, introduciendo mínimos reajustes y adaptando el sistema según las necesidades. Es por ello que, en el periodo comprendido entre el s. II y la primera mitad del I a.C., el impacto de Roma en la organización política, cultural y social, es poco significativo. A este respecto podría estar haciendo alusión la emisión de las cecas de ciudades de la Tierra Llana como Ituci, la cual acuña con rótulos púnicos (Domínguez, 2000: 64), además de otras donde la simbología de algunos motivos iconográficos tiene un indudable carácter oriental (A, creciente lunar, espigas como posible representación de la diosa Tanit), casos de Onoba, Ilipla y Ostur. Ello reflejaría, aún, el peso de la tradición y la cultura púnica en una ciudad a la que se le permite mantener sus tradiciones y su organización política, social, etc. símbolo quizás de un pacto o buen comportamiento durante el proceso de conquistas. De ello se infiere el todavía fuerte arraigo de las poblaciones de la campiña onubense a una tradición cultural púnica y su resistencia a las nuevas corrientes culturales. Obviamente en un momento de la segunda mitad del s. I a.C., con posterioridad a Ategua, la actividad de César se dejaría sentir no solo en la extensión del ius latii a nivel general en la Ulterior, sino en la desaparición de este bilingüismo en las emisiones locales. Como ya apuntara García y Bellido, si eso fue consecuencia de una disposición oficial no lo conocemos, pero refleja desde luego una política dirigida a borrar los aspectos culturales indígenas para sustituirlos por los romanos (García y Bellido, 1967: 11).

Con ello tratamos de reflejar como Roma, a diferencia de la Sierra, encuentra a su llegada a la Tierra Llana un territorio urbano totalmente organizado, estructurado, jerarquizado, con una fuerte identidad cultural heredera en última instancia del mundo púnico-turdetano, de modo que no le interesa trastocar esa realidad preexistente $\mathrm{y}$, por tanto, el modelo de implantación pasaba por mantener y potenciar los esquemas que encuentra, hasta que llegado el momento en la coyuntura del desarrollo de la segunda mitad del s. I a.C. se decida a modificarla sólo en parte. Además, 
durante el siglo II y la mayor parte del I a.C., hasta la llegada de César y sus medidas revolucionarias, las políticas de la administración romana en lo tocante a materia de establecimientos coloniales, o promociones jurídicas fuera de Italia, eran básicamente inexistentes, encontrando una fuerte oposición senatorial ante cualquier medida que se moviese en esos términos. Ello muestra un panorama en el que la continuidad será la nota dominante, donde no existe ni por parte de la administración romana planes de integración jurídica, ni por la de las ciudades turdetanas de este territorio deseos de incorporarse a ella, ya que como se aprecia, no sólo en el territorio onubense sino en todo el área turdetana, existe una continuidad cultural.

Será con César y Augusto, sobre todo con el primero, cuando se produzca una ruptura importante hasta antes no conocida. Como consecuencia del enfrentamiento civil, que tendrá en el ámbito hispano uno de sus principales escenarios, y muy especialmente en el territorio de la Ulterior, el otorgamiento de la ciudanía y las promociones jurídicas a las comunidades que le habían sido fieles e incluso a aquéllas que representaban un punto estratégico en el conjunto de su política provincial modificarán el mapa jurídico de todo el territorio turdetano. Como consecuencia de estas medidas surgirán establecimientos coloniales en las antiguas ciudades que habían mostrado oposición a César; tal y como apunta Olivares se puede afirmar que en la Baetica no existe una sola fundación colonial de época cesariana que hubiera mostrado su fidelidad al dictador desde los primeros momentos de la guerra (Olivares, 1998: 157), con lo que veían en sus territorios el establecimiento de colonias de castigo tal y como sucedió con Urso, Hispalis, etc. Estas medidas políticas desarrolladas por el dictador no se dejaron sentir en los núcleos de la Tierra Llana, dado que mantuvieron su categoría, sin ver modificados su estatus jurídico, de lo que se podría deducir que su participación en la confrontación civil fue o bien escasa, es decir, se mantuvieron neutrales, o bien apoyaron al bando pompeyano ¿habría que intuir por tanto que las ciudades de la Tierra Llana permanecieron del lado de Pompeyo, y por ello no obtuvieron ningún tipo de promoción jurídica o privilegio?. De haber sucedido esta última opción se podría entender que éstos no obtuvieran ningún favor de César, lo que daría sentido a por qué una zona de gran interés económico, especialmente agrario, no entró a for- mar parte de los planes del dictador en la configuración del nuevo mapa político del Bajo Guadalquivir. Sin embargo, resulta tremendamente extraño cómo, de haber participado en la contienda de parte del lado Pompeyano, no se hubieran desarrollado medidas de castigo como la asignación de veteranos, la división del territorio, etc. Es decir, de haber sido un territorio poco leal a César, bien por su participación activa o pasividad ante los acontecimientos ¿por qué se deja este amplio territorio sin el control de una comunidad leal, ya hubiera sido un municipio o el establecimiento de una colonia? Las fuentes que recogen los acontecimientos se muestran para el territorio onubense, cuanto menos, en un profundo silencio. Con todo, nos movemos en el plano de la mera conjetura, y sea como fuere, lo cierto es que los núcleos de la campiña onubense, Ilipla, Ostur, e Ituci, no vieron una promoción jurídica de su estatus, ni por supuesto la deducción de ningún establecimiento colonial con la instalación de veteranos que supusieran un posible punto de control en un territorio propompeyano, como sucede con Urso, o Hispalis, pasando en el cambio de Era sin mayores desajustes con respecto a etapas anteriores. Ni siquiera para el periodo augusteo, sobre todo en los primeros momentos de su principado, se deja entrever el más mínimo indicio de una posible promoción jurídica a municipium y mucho menos a colonia.

\section{CONSIDERACIONES Finales}

Por todo lo dicho anteriormente y a modo de cierre, podemos intuir procesos de implantación diversos, que llevaron parejos distintos modelos de municipalización para el territorio onubense.

Por un lado, en el territorio de la Sierra, el proceso de implantación pasaba necesariamente por la creación de una estructura desde cero, el sustrato cultural, tradicionalmente insumiso, con el problema del bandolerismo y la inexistencia de un mundo urbano fueron premisas que condicionaron, tras las promociones probablemente cesarianas de la Baeturia Celtica, la creación y promoción de un enclave como el de Arucci durante el gobierno de Augusto. Con ello se dotaba al territorio de la Beturia de los mecanismos necesarios, esto es, civitates y la promoción de las mismas para así introducirla de lleno en la Provincia Baetica. De esta forma para el cambio de Era se consigue crear un círculo de ciudades privilegiadas, garantizando la seguridad y prosperidad del territorio. 
Por su parte, en la Tierra Llana se da una dinámica totalmente opuesta a la de la Sierra. Es un territorio de ciudades, un mundo urbano bien definido y fuertemente jerarquizado, donde se ejerce un fuerte control territorial, heredero en última instancia de la administración cartaginesa, y con un sustrato cultural mucho más permeable al cambio de potencia dominadora. Por todo, la administración romana no siente la necesidad de otorgar privilegios, de crear una estructura política que garantice la seguridad, máxime si durante el proceso de conquistas y de guerras civiles las comunidades de la campiña en líneas generales entran en la órbita de Roma sin mayores roces. De hecho, hasta las medidas de Augusto no se notarán modificaciones importantes en el área con la promoción del oppidum de Onoba a colonia - eso si no había visto alguna modificación anteriormente con César - con las repercusiones en el ámbito jurídico y administrativo que conllevaría la implantación de una colonia en un territorio de comunidades peregrinae. Así, con la creación de un enclave privilegiado en la costa, se completaba el mapa político para el territorio más occidental de la Baetica, con lo que ya no tendría sentido ninguna otra promoción, el territorio quedaba estructurado sobre la base preexistente, que a buen seguro aún mantendría su identidad cultural púnica-turdetana, con mínimos cambios, de tal forma que ¿para qué modificar un modelo que funciona? Es por ello, que las comunidades de la Tierra Llana solo podrán alcanzar el derecho de ciudadanía, y ver con ello una promoción de sus comunidades $^{6}$, tras la extensión del ius latii vespasianeo, momento en el que, como queda atestiguado por la epigrafía, entran a formar parte de la nueva situación política jurídica y administrativa promovida por los Flavios en el contexto de Hispania. En cualquier caso, queda de manifiesto como durante la segunda mitad del s. I d.C., y en el contexto de los cambios jurídicos producidos por la extensión del ius latii, en el marco de la Tierra Llana se producen transformaciones jurídicas que afectan a la organización de las ciudades. Será ahora cuando comiencen a aparecer unas élites municipales adscritas a la Qirina tribus, aqué-

6 Habría que dejar abierta la posibilidad a un proceso de promoción augusteo para el núcleo de Ostur.

7 Para el caso concreto de Ostur, el ambiente epigráfico conservado invita a ser cautelosos con una adscripción categó- lla en la que quedan inscritos todos los cives romani que consiguen su promoción jurídica en época flavia, durante la segunda mitad del s. I d.C, momento en el que hacen su entrada en escena nuevas gentes, como los Porcii, Cornelii, Calpurnii, Fabii que unidas a las ya constatadas en la zona norte, Sertorii, Iulii, Baebii, Vibii, y en el entorno de Onoba, Sempronii, completarán el mapa de ciudadanos en el extremo occidental.

Así pues, y a modo de síntesis, podríamos abrir la posibilidad de que si Augusto decidió actuar sobre el enclave onubense, éste hubiera podido conseguir alguna promoción municipal en tiempos de su padre en un primer plan administrativo que pudo llevar a efectos en la zona del Suroeste, siendo completando tan sólo por el primero promoviendo a colonia el puerto onubense. Estas medidas administrativas y territoriales se complementarían, en el occidente de la recién creada Provincia Baetica, con la creación de un nuevo municipio en la sierra, donde era escaso por no decir inexistente- el mundo urbano, y dejando a los oppida de la Tierra Llana Ilipla, Ostur $^{7}$ e Ituci, con el estatuto de peregrinae, ante lo innecesario de tener que promover más cambios jurídicos en un territorio que ya en torno al cambio de Era, y pasadas las confrontaciones civiles, estaba asimilado, estructurado y jerarquizado sobre la base preexistente, donde serían solamente las promociones jurídicas de Onoba, la fundación de Arucci, con sus respectivos cambios administrativos -contributio-, y la expansión de la actividad minera, las modificaciones que la administración romana introduciría, necesitaría y mantendría hasta la ruptura que supusieron, en la dinámica de concesión de privilegios, los momentos flavios. Será en este momento, ante las nuevas expectativas que se abrían con la concesión de un edicto de latinidad, cuando los antiguos oppida que aún no habían conseguido promocionar tuvieran la opción de conseguir tal privilegio. De todo ello se deduce, que si los núcleos de la Tierra Llana, excepción hecha para el puerto de Onoba como hemos visto, no sufrieron ningún tipo de promoción jurídica con anterioridad al periodo flavio fue básicamente porque no entró en los pla-

rica para momentos flavios en lo tocante a su promoción jurídica. Vide Nota 6. 
nes de la administración romana; las características del territorio fuertemente jerarquizado, con numerosos centros urbanos, con unas sociedades fuertemente enraizadas en su cultura púnico-turdetana, hacían innecesario emplear el recurso de promoción jurídica para atraerlas a la órbita romana, máxime si la condición de stipendiaria en los primeros momentos era beneficiario para la administración romana, además muy posiblemente su comportamiento durante el periodo de guerra civil, momento de despegue de las promociones jurídicas no las hizo merecedoras de ello, bien por su neutralidad o adhesión a la causa pompeyana, con lo que ni César primero ni Augusto después sintieron la obligación, deuda política o necesidad de concederla, o incluso cabría preguntarse ¿querrían estos núcleos tal promoción?. Por tanto habrá que esperar a la segunda mitad del s. I d.C. momento en el que se produzca la incorporación de pleno derecho de las comunidades, no sólo de la campiña onubense, sino del Bajo Valle del Guadalquivir, al producirse lo que ya S. Keay denominó hace algunos años como la desintegración de la Turdetania (1992: 309), haciendo alusión a una serie de procesos que desde César y Augusto, y a lo largo del s. I d.C. modificarían la realidad no sólo administrativa y económica, sino la política y en última instancia la cultural pasando esta última por adoptar los modos de vida y formas de organización puramente romanas.

\section{Bibliografía}

ABAD, L. y BENDALA, M. (1996): Urbanismo y ciudad: de las formaciones ibéricas a la consolidación del modelo romano. Actas del XXIII Congreso Nacional de Arqueología (Elche, 1995), vol. II, Elche, 11-20.

ANDREU PINTADO, J. (2004): Edictum, Municipium, y lex: Hispania en época Flavia (6996 d.C.). BAR International series 1293. Oxford.

BENDALA GALÁN, M. (1989): "La génesis de la estructura urbana en la España antigua". CUPAUAM, 16, 127-148.

(1990): "El plan urbanístico de Augusto en Hispania: precedentes y pautas macroterritoriales". Stadtbild und Ideologie. Die Monumenatalisierung hispanischer Städte zwischen Republik und Kaiserzeit, München, 25-42.

(1994): "La ciudad en la Hispania Romana". La Ciudad en el Mundo Romano. Actas del XIV Congreso Internacional de Arqueología Clásica, Tarragona (1993), vol. I, 115-123.
(1995): “El influjo cartaginés en el interior de Andalucía". VIII Jornadas de Arqueología Fenicio-Punicas. Ibiza, 59-74.

(1998): "Fórmulas de promoción y desarrollo urbano y urbanístico en la Hispania tardorrepublicana". Italia e Hispania en la crisis de la República Romana (J. Mangas Ed.). Actas del III Congreso Hispano-Italiano, Toledo, 1993, Madrid, 307-312.

(1999): "La ciudad en la España antigua". Córdoba en la Historia: la Construcción de la Urbe (F.R. García Verdugo, F. Acosta Ramírez, Eds.), Córdoba, 15-36.

(2000-2001): "Estructura urbana y modelos urbanísticos en la Hispania antigua: continuidad y renovación con la conquista romana". Zephyrus, 53-54, 413-432.

(2003 a): "De Iberia in Hispaniam: el fenómeno urbano". De Iberia in Hispaniam: la adaptación de las sociedades ibéricas a los modelos romanos (L. Abad, Ed.), Alicante, 15-35.

(2003 b): La ciudad, ayer y hoy. Discurso de ingreso en la Real Academia de Doctores, Madrid.

(2005): "Urbanismo y romanización en el territorio andaluz: aportaciones a un debate en curso". Mainake, XXVII, ('Arqueología y urbanismo de la Malaca romana: balance y perspectivas'), 9-32.

(2009): "La urbanística antigua en los tres decenios últimos". Estudio preliminar de la $3^{\text {a }}$ edición del libro de A. García y Bellido, Urbanística de las grandes ciudades del mundo antiguo, CSIC, Madrid, 15-68.

BENDALA, M.; FERNÁNDEZ OCHOA, C.; FUENTES, A. Y ABAD, L. (1987): “Aproximación al urbanismo prerromano y a los fenómenos de transición y de potenciación tras la conquista". Los asentamientos ibéricos ante la romanización, Madrid, 121-140.

BENOÎT, F. (1962): "Nouvelles épaves de Provence”. Gallia 20, 147-176.

BERMEJO MELÉNDEZ, J. (2010): "La curia de la ciudad hispanorromana de Arucci/Turobriga". Actas del IV Encuentro de Arqueología del Suroeste (Aracena, Huelva), 999-1010

(2011): Un modelo de implantación municipal y territorial en la Baeturia Celtica: Arucci/Turobriga. civitas et territorium, Universidad de Huelva, Huelva.

(e.p): "Nuevas inscripciones aruccitanas". Actas del V Encontro de Arqueologia do sudoeste peninsular. (Almodóvar, Portugal, Noviembre 2010). 
BERMEJO, J. Y CAMPOS, J. M.:(2010): "La sala de los ediles de Arucci/Turobriga. Officina Ponderaria Aruccitana". Saguntum 41, 9-20.

(e.p.) “Lex Municipalis Aruccitana? Una nueva interpretación para el fragmento de lex municipalis de Cortegana (Huelva)", Latomus.

BERMEJO, J. Y VIDAL, N. DE LA O (2009): "La inscripción de P.P. Sisenninus. Nuevo testimonio evergético en el territorio onubense". Lucentum XXVIII, 201-212.

BRUNT, P. (1977): Conflictos sociales en la Republica romana. Buenos Aires.

CAMPOS CARRASCO, J.M.: (2005): Niebla. Ciudad Tartésica, Romana y Medieval. Huelva.

(2009a): "El urbanismo del municipio romano de Turobriga (Aroche, Huelva)". Estudio de prehistoria y arqueología en homenaje a Pilar Acosta Martínez, (R. Cruz-Auñon Briones y E. Ferrer Albelda, Coords). Sevilla, 465-482.

(2009b): "Estado actual de las investigaciones en la ciudad romana de ¿Turobriga? (Aroche, Huelva)". Andalucía romana y visigoda, ordenación y vertebración del territorio (J. González y P. Pavón, Eds). L'Erma di Bretschneider, Roma, 7-36.

(2011): Onoba Aesturaria. Una ciudad portuaria en los confines de la Baetica. Huelva.

CAMPOS J. M. Y BERMEJO J.: (2007): "Manifestaciones del culto imperial en la ciudad hispanorromana de Turobriga". Actas del Congreso Internacional Culto Imperial: Política y poder. L'Erma di Bretschneider, Roma, 251-274.

(2010): “Arucci y Turobriga y las promociones JulioClaudias en la Baeturia Celtica. A propósito de una nueva aportación epigráfica". AEspA, 83, 133-146.

(e.p.): “Augusto y el proceso de promoción y municipalización en la ciudad de Arucci Turobriga. Una nueva interpretación histórica y arqueológica”. Pyrenae.

CAMPOS, J. M. Y GÓMEZ, F. (1995): “El territorio onubense durante el Bronce Final". Tartessos 25 años después (1968-1993). Jerez de la Frontera (Cádiz), 137-158.

CAMPOS, J. M.; GÓMEZ, F. Y PÉREZ, J.A. (2006): Ilipla-Niebla. Evolución urbana y ocupación del territorio. Universidad de Huelva.

CAMPOS, J. M. Y VIDAL, N. DE LA O (2003): “Las ciudades hispanorromanas del territorio onubense. Estado de la cuestión". Revista d'Arqueología de Ponent, 41-81.
CAMPOS, J. M.; VIDAL, N. DE LA O Y RUIZ, J. (2010): "Acerca de la condición jurídica de Onuba Aestuaria”. Pyrenae Vol. 41-1, 57-69.

DOMERGUE, C. (1990): Les mines de la Péninsule Ibérique dans L'Antiquité Romaine. Collectión de L'École Française de Rome, 127. Roma.

DOMÍNGUEZ MONEDERO, A. J. (2000): “Monedas e identidad étnico-cultural de las ciudades de la Bética". Los cartagineses y la monetización del Mediterráneo Occidental. Anejos de AespA XXII (M ${ }^{a}$ P. García Bellido y L. Callegarín, Coords.). Madrid, 59-74.

GARCÍA Y BELLIDO, A. (1967): "La latinización de Hispania”. A.E.A. 40, 3-29.

GIMENO, H.; MARTÍN, E. C. Y PÉREZ, J.A., (2010): "Un pedestal de estatua con inscripción de Pajaritos (Huelva)". Huelva en su historia 13, 51-62.

GÓMEZ，F. Y CAMPOS, J.M. (2000): “Arqueología Urbana en Huelva: Las últimas evidencias". Anales de Arqueología Cordobesa no 11, 155-176.

GONZÁlEZ FERNÁNDEZ, J. (1989): Corpus Inscriptionum Latinarum de Andalucía. CILA, Vol. I. Sevilla.

GONZÁleZ， J. Y PÉREZ， J.A. (1987): “La Romanización en Huelva". Huelva y su Provincia, II. Cádiz.

HENDERSON, M. I. (1942): "Julius Caesar and Latium in Spain". The Journal of Roman Studies. Vol. 32. Oxford, 1-13.

KEAY, S. (1992): "The romanisation of turdetania". Oxford Journal Archaeology 11(3). Oxford, 275-315.

KNAPP, R. C. (1977): Aspects of the roman experience in Iberia 206-100 B.C. Anejos de Hispania Antiqua. IX. Vitoria.

LAUBENHEIMER, F. (1973): "Recherches sur les lingots de cuivre et de plomb d'èpoque romaine dans les regions de Languedoc-Roussillon et de Provence-Corse". RANarb. Suppl. 3.

LE ROUX. P Y TRANNOY, A. (1973): “ Rome et les indigenes dans le nord-ouest de la peninsule ibèrique". Problemes d'epigraphie et d'histoire. $M C V, 9$. Madrid, 177-231.

MARÍN DÍAZ, M. A. (1988): Emigración, Colonización y municipalización en la Hispania republicana. Granada.

MORALES RODRÍGUEZ, E. Mª :

(2001): "Consideraciones sobre la municipalización flavia en época romana". Florentia Iliberritana: revista de estudios de antigüedad clásica, 307-314. 
(2003): La municipalización Flavia de la Bética. Granada

OLIVARES PEDREÑO, J. C. (1998): Conflicto político y promoción jurídica de comunidades en el occidente romano (133 a.C.-174 d.C.). Alicante.

PÉREZ MACÍAS, J.A. (2006): La huella de Roma. Huelva.

PÉREZ, J.A.; MARTINS, A.; BUSTAMANTE, M. Y DELGADO, A. (2009): "De Praesidium a Vicus Metallum: el poblado minero en el suroeste peninsular". Andalucía romana y visigoda, ordenación y vertebración del territorio (J. González y P. Pavón, Eds). L'Erma di Bretschneider, Roma, 37-64.

SCHATTNER, T. (2007): "Dos estatuas Claudias en el museo de Riotinto". Las minas de Riotinto en época Julio-Claudia. (J. A. Pérez y A. Delgado, Eds). Huelva, 207-226.
STYLOW, A. (1986): “Apuntes sobre epigrafía de época Flavia en Hispania”. Gerión, 4, 285-311.

(1995): "Apuntes sobre tribus romanas en Hispania". Veleia 12, 105-123.

THOUVENOT, R. (1940/1973): Essai sur le province romaine de Bètique. Bibliothèque des cole Françaises D'athenes et de Rome 149. París.

VIDAL TERUEL, N. DE LA O (2007): Análisis arqueológico de la romanización en el territorio onubense. Huelva. 
